\title{
Challenges of Measuring Performance of the Sales and Operations Planning Process
}

\author{
Hana Hulthén \\ Department of Industrial Management and Logistics, \\ Lund University, 221 00, Lund, Sweden \\ E-mail: hana.hulthen@tlog.lth.se (Corresponding Author) \\ Dag Naslund \\ Department of Industrial Management and Logistics, \\ Lund University, 221 00, Lund, Sweden \\ E-mail: dag.naslund@tlog.lth.se and \\ Department of Management, \\ University of North Florida, FL 32224, Jacksonville, USA \\ E-mail: dnaslund@unf.edu \\ Andreas Norrman \\ Department of Industrial Management and Logistics, \\ Lund University, 221 00, Lund, Sweden, \\ E-mail: andreas.norrman@tlog.lth.se
}

\begin{abstract}
The purpose of this study is to identify and structure challenges of measuring performance of the Sales and Operations Planning (S\&OP) process. A multiple case study methodology was applied. Qualitative data was collected via 22 structured interviews with managers from six case companies in various industries. A process oriented framework was proposed by structuring the challenges based on two key areas of process performance (effectiveness and efficiency) and different maturity levels of the process. A major challenge for all the cases, regardless of their maturity level, relates to defining of cross-functional trade-offs measures. Another major challenge was alignment of measures with business strategy and reward system. Additional common challenges for the different maturity levels were also found. While confirming some challenges from previous research, this study also finds new challenges, especially for more mature levels. Examples are standardization to support unbiased decision making, but also customization of measures for various organizational levels, and visualization of findings from the measurement to facilitate analysis. However, future research must validate and extend the results in other industries. The results offer challenges from a process oriented view and can serve as insights for managers when designing and implementing the S\&OP process measures, or advancing from one maturity level to another. This research enhances understanding of the challenges to measure the S\&OP process performance and adds to the $S \& O P$ literature and performance measurement literature.
\end{abstract}

Keywords: challenges, performance measures, sales and operations planning process, $s \& o p$ process, cross-functional integration

\section{INTRODUCTION}

Sales and Operations Planning (S\&OP) can be described as both a long term planning tool to balance demand and supply and as a cross-functional decision making process to align operational activities with strategic goals. In the S\&OP process, functional plans are synchronized into an integrated set of cross-functional, tactical plans (Wagner et al., 2014; Thomé et al., 2012a; Grimson and Pyke, 2007). With these plans, decisions can be coordinated and based on overall business performance as opposed to functional ambitions (Thomé et al., 2012b; Godsell et al., 2010), leading to improved resource allocation and value for customers at the least possible cost (Godsell et al., 2010; Cecere et al., 2009; Milliken, 2008). Properly implemented, S\&OP should thus lead to increased customer satisfaction (effectiveness) and sales as well as cost reduction (efficiency) (Grimson and Pyke, 2007).

S\&OP differs from the traditional planning process in four ways. First, the time frame is long term (often more than a year) in order to identify future needs. Second, the S\&OP process is a higher level planning process as opposed to more functional and operational planning processes. These aspects are critical as the process allows a company to proactively identify and manage future potential imbalances in the supply-demand relationship (Thomé et al., 2012a; Hayashi et al., 2009; Zailani et al., 2008). Third, senior management is significantly involved in the process in order to establish consensus among functional managers. Fourth, the S\&OP process is inherently cross-functional in nature (Oliva and 
Watson, 2011). Thus, to some extent, S\&OP can also be described as a cross functional, process-oriented change approach which strives to increase both corporate effectiveness and efficiency.

Given the increased interest in S\&OP over the last decade, general descriptions of challenges associated with the design and implementation of the S\&OP process exist (Wagner, et al., 2014; Grimson and Pyke, 2007; Bower 2005). However, research related to measuring the S\&OP process performance is more limited (Thomé et al., 2012a). While, Hulthén et al (2016), for example, developed a process oriented framework for measuring S\&OP, they are not addressing challenges related to measuring the S\&OP process performance. Existing literature is scattered and only provides broad statements regarding design, implementation as well as challenges related to measuring the process. Some examples include the focus on functional performance (e.g. sales, production, and finance), rather than on process performance, the application of too many measures, and limited alignment with business strategy and reward systems (Tuomikangas and Kaipia, 2014; Thomé et al., 2012a; Grimson and Pyke, 2007).

Furthermore, the challenges related to measuring performance of the S\&OP process are primarily discussed in practitioner articles (e.g. Lapide, 2005; Bower, 2005) and consultancy reports (e.g. Aberdeen Group 2009; Cecere et al., 2009). The academic literature is rather insufficient (e.g. Grimson and Pyke, 2007). There is a lack of empirically based studies that focus on an in-depth, systematic identification and structuring of the measurement challenges. It is thus not surprising that both academic and practitioner S\&OP literature emphasize the need to increase the insight of the performance measurement challenges since their limited understanding might impair efforts to design and implement S\&OP performance measurement systems (Tuomikangas and Kaipia, 2014; Thomé et al., 2012a). Hence, the purpose of this paper is to identify and structure challenges of measuring performance of the S\&OP process.

\section{FRAME OF REFERENCE}

\subsection{S\&OP Process Maturity Levels and Measurement Challenges}

Existing research indicates that organizations have reached different levels of S\&OP process maturity. Some practitioner literature use three levels (e.g. Aberdeen Group, 2009) while the framework by Grimson and Pyke (2007) is based on five maturity levels. Another frequently mentioned framework by Wagner et al., (2014) has six levels (Table 1). In terms of measurement, maturity levels 0 or 1 indicate no measures, while level 2 would mean a reactive approach. Maturity level 3 would be a fairly standard measurement approach, level 4 is advanced, and finally level 5 would represent a proactive approach. The main measurement challenges for levels 0 and 1 are difficulties related to lack of S\&OP measures and ability to monitor process performance. For levels 2 and 3, challenges are gaps in alignment of measures across different organizational levels and that meeting efficiency is not monitored (Wagner et al., 2014; Grimson and Pyke, 2007). For levels 4 and 5, the challenge is to design measures for profit optimization rather than to only focus on revenues or least costs. It involves establishment of a target profit and access to detailed cost and product information to determine trade-offs among demand and supply alternatives (Aberdeen Group, 2009) However, achievement of maturity level five is very rare among organizations (Grimson and Pyke, 2007).

Table 1 Measurement challenges related to maturity levels of the S\&OP process

\begin{tabular}{|c|c|c|c|c|c|}
\hline \multicolumn{6}{|c|}{ Measurement challenges related to maturity levels of the S\&OP process } \\
\hline \multicolumn{6}{|c|}{ Wagner et al., (2014) } \\
\hline $\begin{array}{l}\text { Level } 0 \\
\text { Undeveloped }\end{array}$ & $\begin{array}{l}\text { Level } 1 \\
\text { Rudimentary }\end{array}$ & $\begin{array}{l}\text { Level } 2 \\
\text { Reactive }\end{array}$ & $\begin{array}{l}\text { Level } 3 \\
\text { Consistent }\end{array}$ & $\begin{array}{l}\text { Level } 4 \\
\text { Integrated }\end{array}$ & $\begin{array}{l}\text { Level } 5 \\
\text { Proactive }\end{array}$ \\
\hline $\begin{array}{l}\text { No tracking of } \\
\text { planning } \\
\text { performance }\end{array}$ & $\begin{array}{l}\text { KPI's sporadically } \\
\text { managed; not aligned } \\
\text { cross-functionally, with } \\
\text { strategy, reward }\end{array}$ & $\begin{array}{l}\text { KPI's partly aligned } \\
\text { cross-functionally, with } \\
\text { strategy and incentives }\end{array}$ & $\begin{array}{l}\text { Internal alignment } \\
\text { of measures not } \\
\text { performed }\end{array}$ & $\begin{array}{l}\text { Irregularly performed } \\
\text { internal alignment of } \\
\text { measures }\end{array}$ & - \\
\hline \multicolumn{6}{|c|}{ Grimson and Pyke (2007) } \\
\hline $\begin{array}{l}\text { Stage } 1 \\
\text { No S\&OP }\end{array}$ & $\begin{array}{l}\text { Stage } 2 \\
\text { Reactive }\end{array}$ & $\begin{array}{l}\text { Stage } 3 \\
\text { Standard }\end{array}$ & $\begin{array}{l}\text { Stage } 4 \\
\text { Advanced }\end{array}$ & & $\begin{array}{l}\text { Stage } 5 \\
\text { Proactive }\end{array}$ \\
\hline $\begin{array}{l}\text { Lacking } \\
\text { information } \\
\text { for decision } \\
\text { making }\end{array}$ & $\begin{array}{l}\text { Measurements of meeting } \\
\text { the sales plans dominate }\end{array}$ & $\begin{array}{l}\text { Meeting efficiency not } \\
\text { monitored }\end{array}$ & $\begin{array}{l}\text { Participation in proc } \\
\text { suppliers and custor } \\
\text { the process }\end{array}$ & $\begin{array}{l}\text { s not evaluated; } \\
\text { ars not asked to evaluate }\end{array}$ & $\begin{array}{l}\text { Measuring profit } \\
\text { optimization is } \\
\text { challenging }\end{array}$ \\
\hline \multicolumn{6}{|c|}{ Aberdeen Group (2009) } \\
\hline & Laggards & & Industry Average & & Best in Class \\
\hline Low performan & & Medium performance on & & & \\
\hline \multicolumn{5}{|c|}{$\begin{array}{l}\text { Express the S\&OP plan in terms of revenue and margins; high-level reporting designed for executive management; proactively } \\
\text { monitor daily performance against S\&OP measures to be alerted about deviations }\end{array}$} & - \\
\hline
\end{tabular}




\subsection{Challenges of Measuring The S\&OP Process Performance: A Framework}

We define the S\&OP process performance, based on process effectiveness and efficiency. Effectiveness represents "...the extent to which customer requirements are met" and efficiency refers to "how economically the organization's resources are utilized when providing a given level of customer satisfaction" (Neely, 1998:5). Furthermore, we combine the two perspectives and van Weeles (2014) framework for measuring purchasing process performance. Even though the purchasing process obviously is different from the $\mathrm{S} \& \mathrm{OP}$ process, the analogy works as the issue at hand is measuring cross-functional process performance and as van Weele (2014) also applies the effectiveness and efficiency terminology. As a result of merging Neely's (1998) and van Weele's (2014) work, a framework was developed in order to systematically structure the challenges of measuring the S\&OP process performance. In the framework, S\&OP process performance is divided into $\mathrm{S} \& O P$ process effectiveness and $\mathrm{S} \& O P$ process efficiency (Figure 1).

The $S \& O P$ process effectiveness can be divided into two areas: corporate effectiveness and corporate efficiency as the goal of the S\&OP process is to satisfy the goal of the customer of the process (i.e. the corporation). Thus, if the $\mathrm{S} \& O P$ process is successful, the corporation should, ideally, increase both its corporate effectiveness and its corporate efficiency. Corporate effectiveness concerns customer satisfaction (i.e. the external customer). Measures thus include various aspects of achieving customer satisfaction. Corporate efficiency concerns resources allocation and includes measuring various aspects of resource allocation.

Therefore, the challenges of measuring the S\&OP process effectiveness comprise of challenges related to measuring corporate effectiveness (customer satisfaction) and corporate efficiency (resource allocation). In practitioner literature, the challenges in measuring corporate effectiveness relate mainly to tracking the measurements over time. Examples include challenges to measure variance to baseline forecast and budget, and adherence to sales, marketing and operations plans (Lapide, 2004).

Regarding corporate efficiency challenges, the literature discusses issues with monitoring of products going through life cycle changes. It allows an organization to avoid obsolete inventory, sales execution problems and poor forecasts (Bower, 2005). Related to both corporate effectiveness and efficiency, several authors identified challenges of determining trade-offs measures crucial for aligning the often contradicting cross-functional goals, and monitoring of strategy progress (Tuomikangas and Kaipia, 2014; Caplice and Sheffi, 1995).

$S \& O P$ process efficiency refers to resource allocation for conducting the S\&OP process itself. It includes measuring aspects related to how well the activities that are part of the S\&OP process are organized and managed (Wagner et al., 2014; Cecere et al., 2009).

Challenges of measuring S\&OP process efficiency relate to how well the activities that are part of the S\&OP process are organized and managed. Previous literature discusses challenges to proactively monitor performance against S\&OP measures on a regular basis (Bower, 2005), to evaluate different planning scenarios (Cecere et al., 2009), and to regularly revise the current measures (Grimson and Pyke, 2007). Organizations seem to struggle not only with assigning and monitoring accountability for the S\&OP measurements and its unbiased evaluation (Grimson and Pyke, 2007; Bower, 2005; Lapide, 2004), but also with resistance to have work publicly evaluated (Bower, 2005). To enhance S\&OP meeting efficiency, the implementation of S\&OP workbench software is suggested in order to offer a holistic view of supply and demand to assist the S\&OP meetings (ibid).

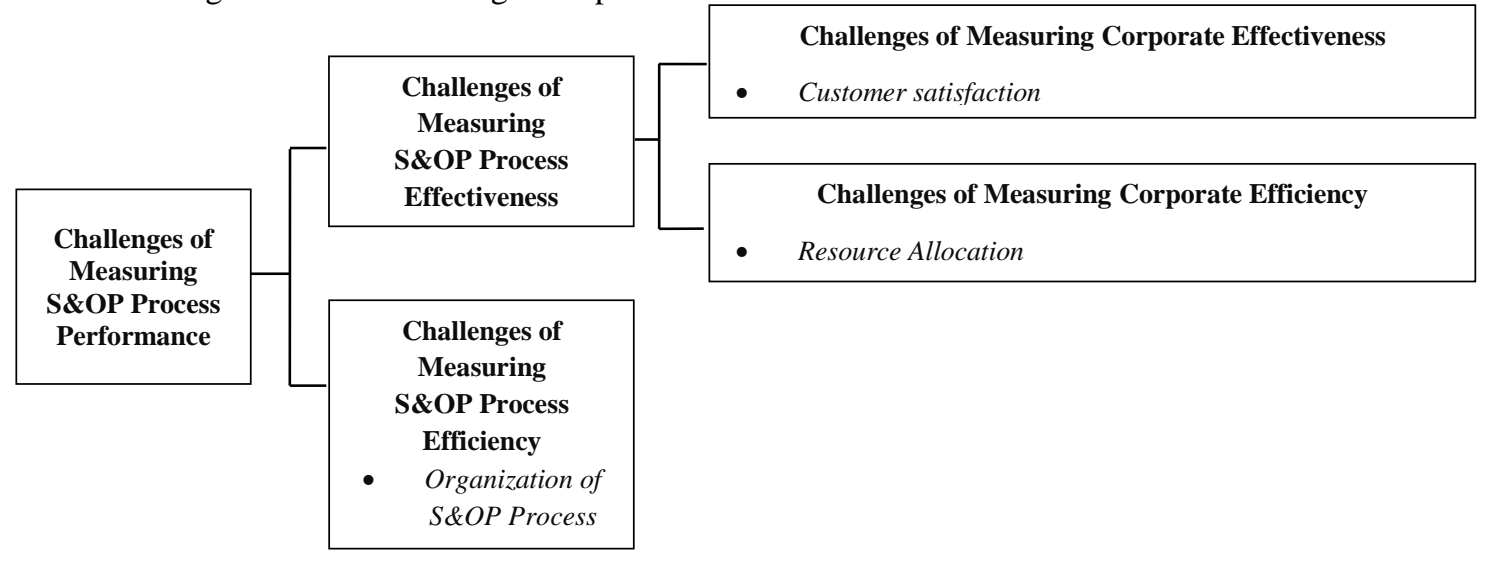

Figure 1 Performance Measurement Challenges Of The S\&OP Process - A Framework

\section{RESEARCH DESIGN}

This research is grounded in a multiple case study method to extend existing theory on performance measurement challenges of the S\&OP process. Several researchers call for more in depth multi-perspective case studies on this topic (Tuomikangas and Kaipia, 2014; Thomé et al., 2012a). The method further supports the exploratory nature of the purpose (Yin, 2009). In addition, this specific study was one of two studies in an overall research project. Thus, data collection was done in parallel to another study (Hulthén et al, 2016), but the research focus, the unit of 
analysis, the number of analyzed cases and data differs. In this study, the unit of analysis is challenges of measuring performance of $S \& O P$ process. The purposeful sampling criteria were applied to select cases from which in-depth insights can be gained (Dubois and Araujo, 2007).

\subsection{Sample Selection}

The sample comprises of six companies. The case companies were selected from an internally developed survey on a current state of the S\&OP process implementation (answered by 63 companies). The survey answers were reviewed in order to select those case companies that i) stated their perceived S\&OP process maturity level as (2), (3), or (4), according to Grimson and Pyke's, (2007) framework; and ii) their perceived importance of the S\&OP process as 8-10 on the scale 1-10. Those companies which fulfilled these criteria were invited via e-mail or phone to participate in the study. Six companies eventually expressed their interest to be part of the research.

The final sample includes Engineering, Information Technology (InfoTech), Telecom, Energy, Medical Technology (MedTech), and Cosmetics companies (Table 2 ). The headquarters and respondents of the companies are located in Sweden, but their businesses are truly global and operating in several countries. The cases were selected to represent different maturity levels of the S\&OP process. This is assumed to have impact on the type of challenges of measuring the process performance. In terms of maturity levels, one company represent S\&OP maturity level 2, three companies are at level 3, and two companies are at level 4 . In terms of how the companies perceived the importance of the S\&OP process, three companies perceived the importance at level 10; two companies were at level 9, while the final company was at level 8 .

\subsection{Data collection}

In total twenty-two interviews were conducted. Each interview lasted between 30 minutes and three hours. All respondents were directly involved in and/or accountable for the S\&OP process at their respective company. The number of informants and their functions varied across the cases (Table 2). The interviews were conducted face-to-face, recorded and transcribed.

The extensive interview protocol (available upon request) was tested during a pilot interview with one of the case companies (Krause and Ellram, 2014). The modified final protocol includes both structured and semi-structured questions on currently used S\&OP process effectiveness and efficiency measures and related challenges. While the line of inquiry was followed during the interviews, clarifying questions were asked when needed to reduce a potential bias of responses. Additional data, such as company reports, presentations, consulting reports were collected to corroborate the evidence from the interviews (Yin, 2009).

\subsection{Data analysis}

The data analysis included within case and cross-case analysis. In the within case analysis, each individual interview was coded in accordance with the developed framework to identify challenges of measuring S\&OP process effectiveness and efficiency. The results were then synthesized on a case level - i.e. for each company. During the cross-case analysis, axial coding was applied to identify patterns and to aggregate the findings across the cases (Yin, 2009; Miles and Huberman, 1994). This was conducted through an iterative triangulation approach (Krause and Ellram, 2014) where the data were matched with our theoretical framework to arrive at a final framework (finally illustrated in Figure 4).

Table 2 Case Companies And Informants

\begin{tabular}{|c|c|c|c|c|c|c|}
\hline $\begin{array}{l}\text { Case } \\
\text { companies }\end{array}$ & Engineering & InfoTech & Telecom & Energy & MedTech & Cosmetics \\
\hline $\begin{array}{l}\text { S\&OP process } \\
\text { maturity level }\end{array}$ & 2 & 3 & 3 & 3 & 4 & 4 \\
\hline $\begin{array}{l}\text { Importance of } \\
\text { S\&OP process }\end{array}$ & 10 & 10 & 10 & 8 & 9 & 9 \\
\hline $\begin{array}{l}\text { Interviews } \\
\text { (number/ } \\
\text { duration) }\end{array}$ & $\begin{array}{l}1 / 3 \text { hours, } \\
1 / 1 \text { hour, } \\
8 / 30 \mathrm{~min}\end{array}$ & $2 / 2$ hours & $3 / 2$ hours & $4 / 2$ hours & $2 / 2$ hours & $1 / 2$ hours \\
\hline Informants & $\begin{array}{c}\text { Managers: } \\
\text { Measurement/control, } \\
\text { Sourcing, Plant, } \\
\text { Logistics, Production, } \\
\text { Quality, Customer } \\
\text { service }\end{array}$ & $\begin{array}{l}\text { Vice President } \\
\text { Operations, } \\
\text { Demand } \\
\text { Manager }\end{array}$ & $\begin{array}{c}\text { Managers: } \\
\text { Demand Planning } \\
\text { Process, Head of } \\
\text { Demand, } \\
\text { Improvement/ } \\
\text { Performance }\end{array}$ & $\begin{array}{c}\text { Managers: } \\
\text { Regional material } \\
\text { Group, Head of } \\
\text { homecare, Marketing } \\
\text { Intelligence, Market }\end{array}$ & $\begin{array}{c}\text { Managers: } \\
\text { Director Supply } \\
\text { Chain (S\&OP } \\
\text { leader), Global } \\
\text { Operations }\end{array}$ & $\begin{array}{c}\text { Manager: } \\
\text { Senior Director } \\
\text { Global Business } \\
\text { Development } \\
\text { (S\&OP leader) }\end{array}$ \\
\hline
\end{tabular}




\section{CASE DESCRIPTION - CHALLENGES OF MEASURING PERFORMANCE OF S\&OP PROCESS}

The chapter is structured after the maturity levels of the case organizations. We present challenges related to measuring S\&OP effectiveness (Figure 2) and S\&OP efficiency (Figure 3) for each case company.

\subsection{Maturity Level Two - Engineering Case}

4.1.1 Challenges of measuring S\&OP Process effectiveness

The main challenge of measuring corporate effectiveness is to extend the planning beyond short-term reactive reporting based mainly on historical data and risks. The informants stressed the importance of using a longer planning horizon and incorporation of measures such as forecast accuracy, on time delivery, order fill rate, contribution margins into the S\&OP process. Another challenge concerns the defining of an after-sales service metric (e.g. net promoter scores, service forecast accuracy).

Regarding measuring corporate efficiency, the incorporation of operational measures (e.g. slow moving inventory, inventory turnover, ramp up/ down accuracy of products, and production capacity) into the process was highlighted as a main challenge. Currently, they are monitored in isolation as a part of other processes or functions. Additionally, sales related measures are given priority over operations measures.

Associated with both corporate effectiveness and efficiency, defining trade-offs measures to balance supply and demand is also challenging. Examples of trade-off measures include ramp up/ ramp down of products in relation to contribution margins, actual versus planned inventory, and actual versus planned sales.

\subsubsection{Challenges of measuring $S \& O P$ Process efficiency}

Regarding the current Organization of $S \& O P$ process, the major challenge concerns correct design of the S\&OP measures including both supply and demand related measures. Another challenge is lack of transparency. Supply oriented functions perceive transparency to be a challenge when it comes to preparation and sharing of S\&OP related information. Linked to this issue, IT is not sufficiently assisting in the preparation and visualization of the measures. Finally, the Engineering case has not yet established clear routines for conducting S\&OP meetings. Consequently, S\&OP meetings efficiency is not monitored.

\subsection{Maturity Level Three - InfoTech, Telecom and Energy Case}

4.2.1 Challenges of measuring $S \& O P$ Process effectiveness

Associated with corporate effectiveness, a major challenge for InfoTech is to identify an appropriate customer service level that is acceptable for customers and leads to profit optimization. They also find it difficult to agree on an appropriate level of detail (i.e. product family, component) for demand forecast (especially for new products). Forecast accuracy across the organizational functions is also challenging.

Similarly, Telecom finds it difficult to capture forecast deviations due to the current multilevel perspective and lack of standardized measures (e.g. different time horizons, product granularity and product segments). Furthermore, the company is lacking supply plan adherence measures (supply plan vs actual supply to regions) as the supply side is not fully integrated in the current S\&OP process. To identify a unifying measure of costs of S\&OP plans instability (i.e. low S\&OP plan adherence), and to measure total supply chain cost represent yet another challenges.

In the Energy case, an analysis of reasons for demand over- and under-forecasting is perceived challenging (as a supplement to forecast accuracy). Moreover, they need to introduce a supply related measure (e.g. supply plan adherence). The informants stressed the challenge to introduce financial measures (e.g. profit optimization) which would reflect the output/ contribution of the process to the overall business performance.

Concerning corporate efficiency, the InfoTech and the Telecom cases expressed the necessity to extend the currently used new products related measures due to innovativeness of their products. The InfoTech case does measure ramp up accuracy but lacks ramp down accuracy for end-of life products. This could lead to a reduction of obsolete inventory. The Telecom case has deficiencies in monitoring new products introductions. The Energy case finds it challenging to measure the financial contribution (i.e. cost reduction) related to capacity utilization or labor efficiency as a result of implementation of the S\&OP process.

Related both to corporate effectiveness and efficiency, the prevailing challenge concern cross-functional trade-offs measures. In the InfoTech case, the measures are connected to the strategic goals but they are not clearly synchronized into cross-functional trade-offs to optimize profit. The Telecom case experiences difficulties to define trade-offs measures due to lack of process view and complex organizational structure. Their S\&OP process is more silos oriented. The process includes demand planning, while supply planning is not part of it. Also the Energy case lacks a holistic perspective, including both demand and supply side, in their current measurements. Thus, the potential measures need to capture the interface between the demand and supply. 


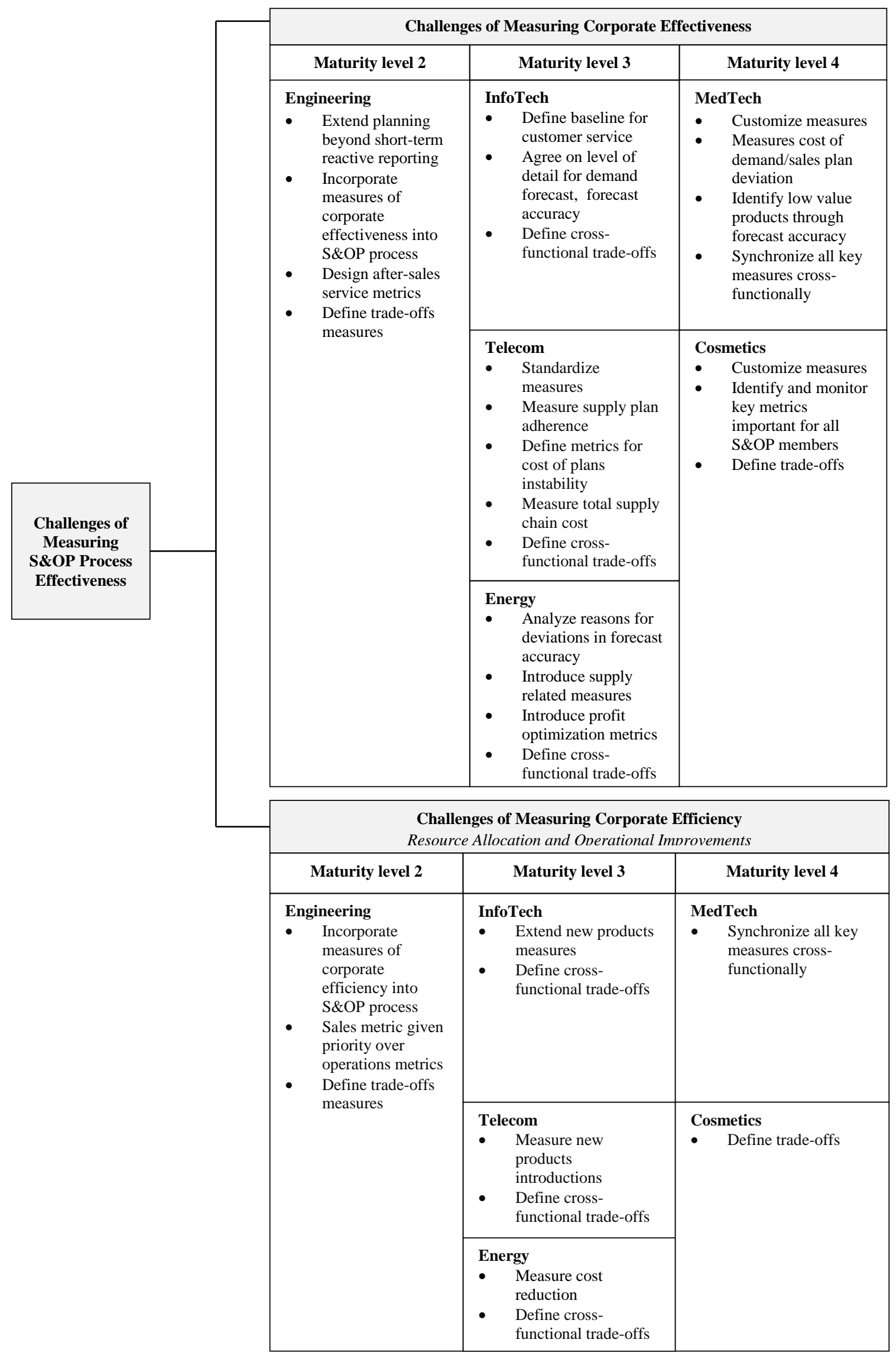

Figure 2 Challenges of measuring the S\&OP Process effectiveness 


\subsubsection{Challenges of measuring $S \& O P$ Process efficiency}

The InfoTech case finds it challenging to link measures such as service level and on-time delivery to sales measures to see the financial impact of their potential imbalance (e.g. lost sales). According to the informants, they need an integrated IT system to perform this analysis efficiently and to obtain a comprehensive overview with ability to visualize the S\&OP measures. Similarly, an appropriate IT system is needed to obtain monthly status reports in relation to the S\&OP plans and thus decrease the currently long feedback loop. Consequently, there is a low efficiency in monitoring the actual S\&OP performance against planned performance.

In the Telecom case, the limited alignment of measures with the reward system does not link accountability and reward adequately. As a result of multiple sources of data used for financial forecast and demand planning, there is a challenge of information inconsistency. The used S\&OP measures are not designed to inform about the process performance. Instead, they are chosen to comply with the meetings' agenda. There are challenges in baseline identification, lack of benchmarking with other companies, and standardization of measures to enhance comparability.

In the Energy case, the measures are not connected to the performance of the process. The alignment with business strategy is not clear; however, the informants concluded that the measures are not opposing the strategy. The main issues are related to deficiencies in information quality (e.g. demand data), availability and reliability to support decision making. There is lack of measures that capture the meeting efficiency. The case expressed difficulty to define such measure. One informant suggested using ratio of decisions made during the meetings.

\subsection{Maturity Level Four - MedTech and Cosmetics Case}

\subsubsection{Challenges of measuring $S \& O P$ Process effectiveness}

For the MedTech case, the challenges of corporate effectiveness relate to customization of measures for the various organizational levels (i.e. generic or detailed levels). According to the informants, the case has also issues to measure the costs associated with deviation between demand forecasts and sales plans. Additionally, to monitor forecast accuracy in monetary terms is problematic as deviation of low value products might have negative impact on customer service level. Equally, the Cosmetics company expressed a need to customize key measures for different target groups (e.g. for the executive meeting, S\&OP review meeting). Moreover, they struggle to identify a set of key measures which are considered important for all members of the S\&OP team.

Although the MedTech case has defined process oriented trade-offs (e.g. demand plan versus production plan; actual inventory levels versus inventory targets; inventory levels versus capacity levels; actual financial performance of plans versus business targets), they still have challenges of corporate efficiency such as some key measures that are not synchronized. This may lead to different internal opinions about whether to increase or decrease the S\&OP plans.

The Cosmetics case understands the relationship between e.g. inventory levels versus actual sales, and sales plan versus demand forecast. However, the informant says that trade-offs measures, to balance demand and supply side, are not defined and used. Instead, the above listed measures are monitored in isolation.

\subsubsection{Challenges of measuring S\&OP Process} efficiency

In the MedTech case, there are deficiencies in the alignment of measures with strategy and reward system. While high-level reporting is designed for executive management, the informants stressed a challenge to visualize and present the measures in a right way to enhance decision making. To enhance the situation, a compatibility of currently used ERP systems is needed to avoid manual calculation of some measures (e.g. customer service level).

In the Cosmetics case, the main challenge is that strategy goals are given less priority when performance on other key measures (e.g. sales) is insufficient. Moreover, the company lacks measures to constantly evaluate planning scenarios to eliminate, for example, lack of inventory during promotions.

\section{ANALYSIS AND DISCUSSION}

In the final framework in Figure 4, the identified challenges were synthesized and clustered to arrive at a representative set of clusters for each of the maturity levels.

\subsection{Challenges of Measuring S\&OP Process Effectiveness}

The main observed challenge related to measuring $S \& O P$ Process effectiveness is to Define cross-functional trade-offs measures. Only one case (MedTech, at maturity level 4) implemented such measures. This finding corresponds to the previous S\&OP research (Wagner et al., 2014; Grimson and Pyke, 2007) that organizations experience difficulties to align measures across functions. While this challenge is mainly associated with lower maturity levels (i.e. level 2 and 3), our data suggest that this issue exists also in cases perceiving themselves at more advanced maturity level. Also at higher levels (i.e. level 4), the complete synchronization of key measures across functions remains problematic (Grimson and Pyke, 2007; Bower, 2005). Although several researchers stressed importance of implementation cross-functional trade-offs to align often contradicting functional goals (Tuomikangas and Kapia, 2014; Lapide, 2004), the literature is rather scarce on providing specific examples of such measures. Below we discuss additional challenges of measuring corporate effectiveness and efficiency. 


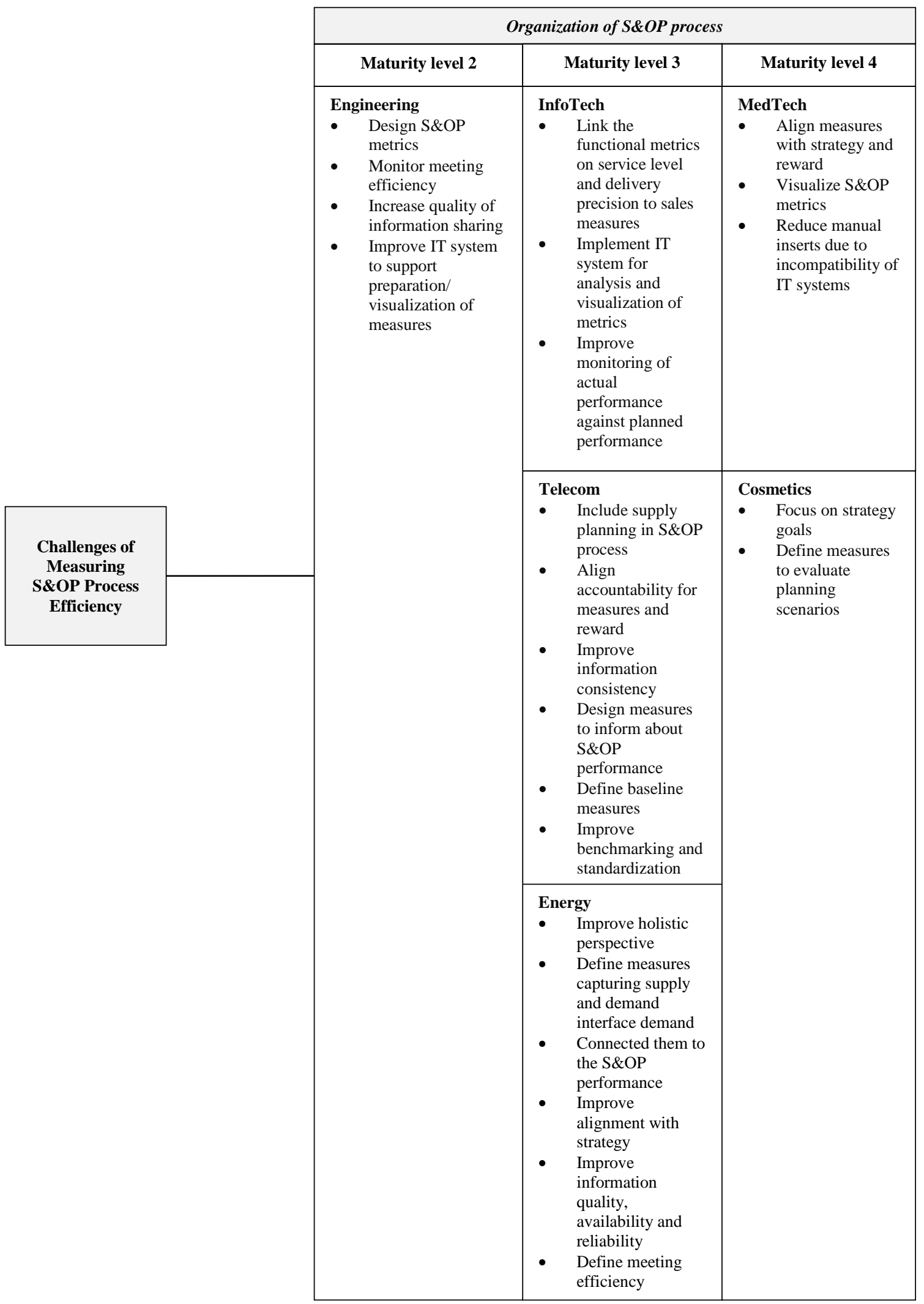

Figure 3 Challenges Of Measuring The S\&OP Process Efficiency 


\section{Challenges of measuring corporate effectiveness}

Associated with corporate effectiveness, rather basic challenges were observed in the maturity level 2, such as Extension of planning horizon, and Incorporation of measures into $S \& O P$ process. Extension of planning horizon reflects the challenge of extending the planning beyond only short term reactive reporting. This corresponds to findings by Bower (2005) and Lapide (2004) who discuss the challenge of a longer monitoring and planning horizon to identify future trends and threats. The challenge of Incorporation of measures into S\&OP process refers to including of corporate effectiveness measures (e.g. order fill rate, on time delivery) into the $\mathrm{S} \& \mathrm{OP}$ process rather than to monitor those at a functional level. While the literature suggests that the lack of S\&OP measures is associated with organizations at maturity level 1 (Wagner et al., 2014; Grimson and Pyke, 2007), our findings show that this challenge is prevalent also at companies perceiving themselves at level 2.

Related to the maturity level 3 , our cases exhibit more advanced type of challenges compared to the level 2 which are associated with Standardization of measures, Defining profit optimization measures, and Defining supply related measures. Standardization of measures refers to agreement on a standardized level of detail (e.g. product family, component level) for monitoring of e.g. forecast accuracy. Currently, there is a multilevel perspective in terms of different time horizons, product granularity and product segments that needs to be captured in such measure. Standardization is vital to avoid misunderstanding of the current situation and a biased decision making. Although, previous literature discusses that the S\&OP process should be conducted at aggregated product family level (Thomé et al., 2012a), it is less clear about the level of detail (e.g. product family, component) at which the performance should be measured.

The challenge of Defining profit optimization measures was in previous research discussed at the highest maturity level 5 (Grimson and Pyke, 2007). However, our findings show that companies already at maturity level 3 discuss this issue. The challenge of Defining supply related measures highlights the absence of supply related measures (e.g. supply plan adherence) as the focus seems to be rather on demand related measures. This corroborate partly with findings by Grimson and Pyke (2007), although the authors associated this challenge with maturity level 2 .

The nature of the observed challenges at level 4 cases was more sophisticated compared to the lower levels. It included primarily Customization of measures for various organizational groups and levels, and not just for the executive management as suggested by Aberdeen Group, (2009) and Bower (2005). Another observed challenge entails Identification of KPIs vital for all S\&OP team members. It refers to the struggle to identify a set of key measures which are considered important for all members of the S\&OP team.

\section{Challenges of measuring corporate efficiency}

Concerning corporate efficiency, in level 2, rather basic challenges were found related to Incorporation of measures into $S \& O P$ process, and Reduce dominance of sales measures. The challenge of incorporation of measures into S\&OP process is similar to that discussed above in relation to corporate effectiveness. On the other hand, by identifying the challenge to reduce dominance of sales measures, our study thus confirms the prioritizing of the sales measures over operations measures as highlighted in literature (Grimson and Pyke, 2007).

In level 3, the data show challenges such as Standardization of measures, Defining cost reduction measures, and Defining new products development measures. Standardization of measures corresponds to the challenge discussed above related to corporate effectiveness. Regarding the challenge of Defining cost reduction measures, our cases were concerned with capturing the cost reduction rate to monitor the improved capacity utilization as a result of the S\&OP process. This would require access to target profit and detailed cost and product information (Aberdeen Group 2009). Associated with the challenge of defining new products development measures, Bower (2005) emphasizes the monitoring of product life cycles to reduce obsolete inventory and lost sales. A similar challenge was observed at the studied cases. In level 4, the challenge of Customization of measures is identical to that discussed above.

\subsection{Challenges of measuring S\&OP Process Efficiency:Cross-functional Integration/Process orientation}

Similarly to S\&OP effectiveness, the data on $S \& O P$ Process efficiency show a set of challenges that are common for several maturity levels. While for level 2 and 3 these challenges are Defining meeting efficiency measures and Information preparation and sharing, at level 3 and 4 two major challenges were identified such as Alignment of measures with strategy and reward, and Visualization of $S \& O P$ measures.

Associated with the Defining meeting efficiency measures, as the case at level 2 has not yet established the S\&OP process properly, it had difficulties to assign measures of its efficiency. The meeting efficiency (e.g. attendance at meetings, pre-meeting work done on time) is not monitored but it is seen as desirable to enhance the process implementation. On the other hand, the level 3 cases did not defined and monitored meeting efficiency with the explanation that they had established clear routines regarding, for example, attendance of all S\&OP member, planning frequency, and thus this measure was perceived as redundant. Another reason was the difficulties to identify measures that would capture how efficient the meetings are.

To deal with the challenge of Information preparation and sharing, the informants at level 2 case stressed implementation of an IT system that would support measuring the process performance. It would also allow for enhanced information transparency and availability. Related to this challenge it is somewhat surprising that organizations perceiving themselves at maturity level 3 still deal with rather basis issues of information consistency, reliability and availability. 


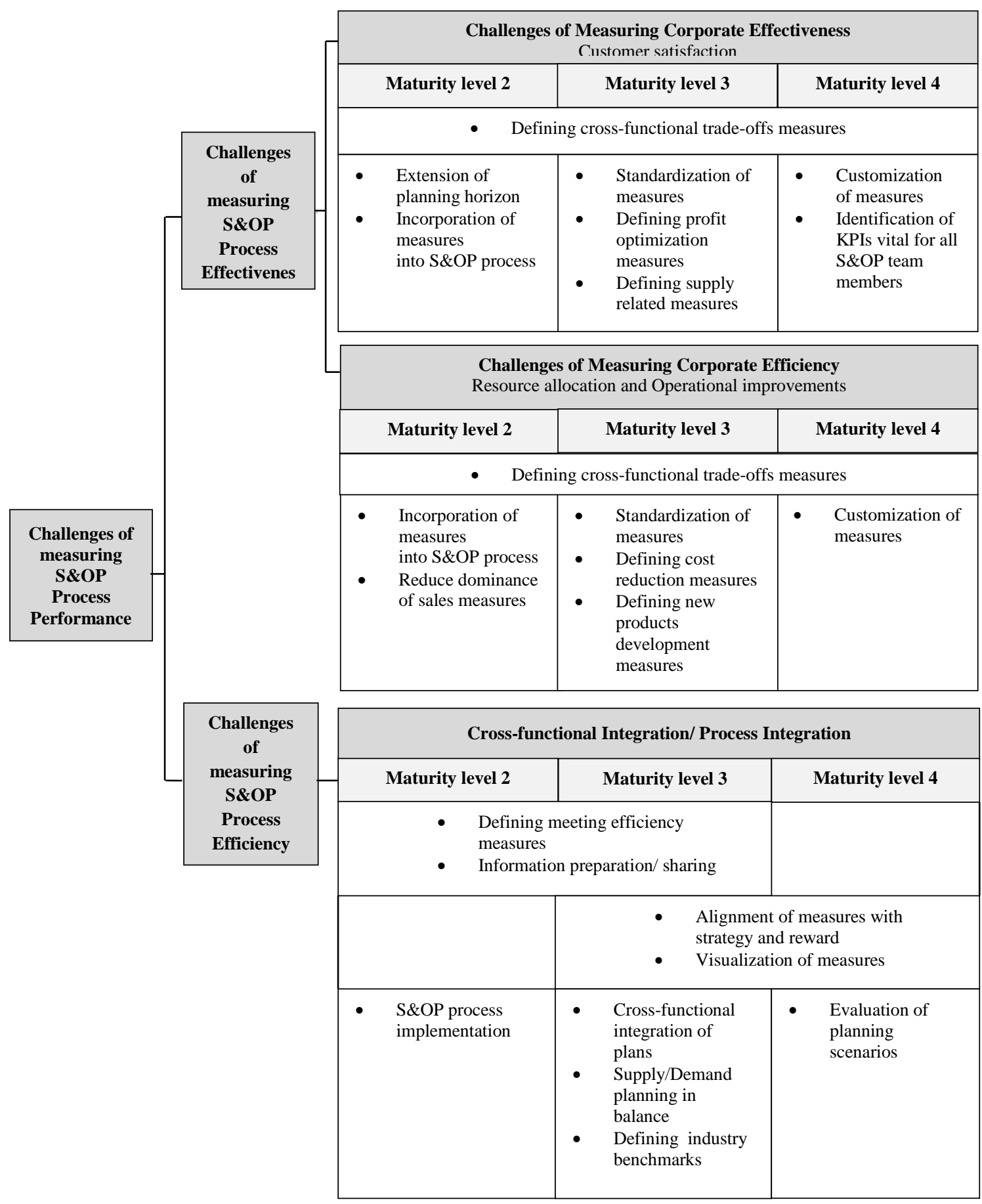

Figure 4 Challenges Of Measuring The S\&OP Process Performance

The challenge of Alignment of measures with strategy and reward relates to the previously discussed issue of defining cross-functional trade-offs and then aligning them with business strategy and reward system (Tuomikangas and Kaipia, 2014; Wagner et al., 2014). One of the cases (Cosmetics, at maturity level 4) reported that monitoring of the strategy progress receives less attention when deviations on other key measures occur. The challenge of Visualizing S\&OP measures entails mainly the lack of an IT system that would assist both in preparation and displaying of the measures, and also in analysis of the reasons for deviations from plans. The literature mentions the importance of IT systems to provide a holistic view of supply and demand (Bower, 2005). However, the issues related to visualization and analysis of the measures has not yet been discussed.

Additional challenges identified at level 2 are in line with previous research (Wagner et al., 2014; Grimson and Pyke, 2007) such as $S \& O P$ process implementation. As has been mentioned previously, the case company has still major deficiencies in establishing the S\&OP process.

At level 3, other identified challenges concern Supply/ demand planning in balance, Cross-functional integration of 
plans, and Defining industry benchmarks. Related to the challenges of Supply/ demand planning in balance, the data show that even cases at rather advanced maturity level 3 had problems to include supply measures into S\&OP measures in order to assess demand and supply plan balance. The challenge of Cross-functional integration of plans refers to insufficient interface between supply plan and demand plan and the planned financial outcomes (e.g. link between planned service level, on time delivery, sales and profit targets). This issue is closely related to the identification of cross-functional trade-offs discussed above (Grimson and Pyke, 2007). The last challenge at level 3, Defining industry benchmarks, concerns establishment of appropriate industry related benchmarks to allow for performance comparison of the S\&OP key measures with other companies within the same industry. Wagner et al., (2014) suggest regular conducting of internal and external S\&OP benchmarks.

At level 4, a major challenge is Evaluation of planning scenarios (previously discussed by e.g. Cecere et al., 2009). In our case, it entails identification of measures for evaluation of various planning scenarios to reduce, for example, lack of inventory during a planned promotion.

\section{CONCLUSIONS}

This multiple case study contributes to the S\&OP theory by confirming some previously identified challenges, yet we also provide additional challenges related to measuring the S\&OP process. Further, we structure the observed challenges in a framework based on S\&OP process effectiveness and efficiency. The findings support previously discussed challenges such as the domineering focus on functional performance rather than on process performance, the application of too many measures, and limited alignment with business strategy and reward systems (Tuomikangas and Kaipia, 2014; Thomé et al., 2012a; Grimson and Pyke, 2007).

The study extends current knowledge by discussing additional challenges, such as standardization, customization, and visualization of measures. Standardization is needed in order to ensure comparability, transparency and comprehensibility. On the other hand, organizations also need to be able to customize measures for various organizational groups and levels. Since they may seem contradictory in nature, both challenges are critical to consider when designing performance measures that are informative as well as contributing to a potential reduction of biases in the decision making process. Thus, existing theory still needs to be developed to increase understanding of these aspects. Another challenge with limited attention in the previous S\&OP literature is visualization of the measures. To some extent, this challenge also highlights the lack of appropriate IT systems.

In our research we also identify challenges for various S\&OP maturity levels. Thus, we provide both academics and practitioners with deeper insights of which specific challenges characterize different S\&OP maturity levels. For practitioners, this knowledge can help them develop their S\&OP process in order to move to the next maturity level. By doing this, previous maturity models (e.g. Wagner et al., 2014; Grimson and Pyke 2007) are complemented.
Several challenges related to $S \& O P$ process effectiveness and efficiency are observed at many levels and can be seen as more general. These include defining crossfunctional trade-offs measures (level 2, 3 and 4); defining meeting efficiency measures, information preparation and sharing (level 2 and 3); alignment of measures with strategy and reward, and visualization of measures (level 3 and 4). One explanation for the occurrence at multiple levels might be the difficult nature of these challenges. Several of these challenges are not unique for the $\mathrm{S} \& \mathrm{OP}$ process, but rather they are challenges for most cross functional processes. Thus, to overcome these challenges will require that the S\&OP community learn from, and collaborate with, other process management academics and practitioners.

Furthermore, challenges such as incorporation of measures into the S\&OP process, and defining supply related measures are in literature primarily associated with lower maturity levels. However, in our cases we observed that these challenges also exist at more advanced maturity levels. On the other hand, our data show that the challenge of defining profit optimization measures was seen as problematic already at level 3, while in literature (e.g. Grimson and Pyke, 2007) it is associated with more advanced levels.

Yet another observation is that the main challenges related to measuring S\&OP process efficiency are challenges of cross-functional integration and process orientation. Therefore, this aspect was added as a key area in the final proposed framework. The more mature level, the more the cases expressed challenges not only to synchronize all key S\&OP measures into cross-functional trade-offs but also to align these measures with business strategy and reward systems. Our study thus confirms how difficult it is, even in more mature S\&OP implementations, to tear down the functional silos and to establish more process oriented, crossfunctional organizations (Tuomikangas and Kaipia, 2014; Grimson and Pyke, 2007). According to Msimangira and Venkatraman (2014), many businesses are still struggling with this kind of supply chain integration silos.

It might be rather difficult to compare the identified challenges between the various maturity levels with those discussed in previous literature as different authors (e.g. Wagner et al., 2014; Grimson and Pyke, 2007) define them differently. Also, our cases could misjudge their perceived maturity levels (based on the framework by Grimson and Pyke, 2007). However, our analysis of the data indicates that their perceptions are to a large extent consistent with the used framework.

The identified challenges of measuring the S\&OP process can assist managers during their process of designing, implementing but also revisiting current S\&OP performance measures. The framework focusing on effectiveness and efficiency aspects of process performance may support organizations in implementing S\&OP measures that enhance both those dimensions, such as the measurement system suggested by Hulthén et al. (2016). Finally, understanding the important but difficult issue of cross-functional measures aligned with strategy and reward systems may guide organizations to become more process oriented. 
A limitation of the study is the sample size of six cases based in Sweden. On the other hand, all cases were studied in depth. Still, more research could validate the results through additional cases representing, for example, all different levels of the S\&OP process maturity (including companies perceived being on the highest level), and in other industries. Furthermore, large scale studies could be conducted to investigate the potential effect of factors such as type of industry or geographical location on challenges of measuring the S\&OP process performance. Future research could address the more mature levels' challenges, reported in this study, such as how to evaluate different planning scenarios or how to use IT and new applications (e.g. Business Intelligence) to better visualize and customize measures for different stakeholders in the S\&OP process. Future studies can examine the challenges of standardization, customization and visualization of S\&OP performance measures. The challenges related to adjustment of S\&OP measurements to changes in strategy would also be valuable to explore, as well as the potential differences in S\&OP measurement challenges as a result of pursuing various supply chain strategies for different type of products (e.g. functional or innovative).

\section{REFERENCES}

Aberdeen Group (2009). Sales and operations planning: integrate with finance and improve revenue. July, pp. 1-23.

Bower, P. (2005). 12 most common threats to sales and operations planning process. Journal of Business Forecasting Fall, pp. 4-14.

Caplice, Ch. and Sheffi, Y., (1995). A review and evaluation of logistics performance measurement systems. The International Journal of Logistics Management 6(1), pp. 6174.

Cecere, L., Barret, J., and Mooraj, H. (2009). Sales and operations planning: transformation from tradition. AMR Research May, pp.1-9.

Dubois, A. and Araujo, L. (2007). Case research in purchasing and supply management: opportunities and challenges. Journal of Purchasing \& Supply Management 13, pp. 170-181.

Godsell, J., Birtwistle, A., and van Hoek, R. (2010). Building the supply chain to enable business alignment: lessons from British American Tobacco (BAT). Supply Chain Management: An International Journal 15(1), pp.10-15.

Grimson, J.A., and Pyke, D.F. (2007). Sales and operations planning: an exploratory study and framework. The International Journal of Logistics Management 18(3), pp. 322-346.

Hayashi, A., Ishii, N., and Matsui, M. (2009). A Theory and tools for collaborative demand-to-supply management in the SCM age. Operations and Supply Chain Management 2(2), pp. 111-124.

Hulthén, H., Naslund, D., and Norrman, A. (2016). Framework for measuring performance of the sales and operations planning process. International Journal of Physical Distribution and Logistics Management, 46(9), pp. forthcoming.

Krause, D., and Ellram, L.M. (2014). The effects of the economic downturn on interdependent buyer-supplier relationships. Journal of Business Logistics 35(3), pp.191-212.

Lapide, L. (2004). Sales and operations planning part I: The process. The Journal of Business Forecasting Fall, pp.17-19.

Lapide, L. (2005). Sales and operations planning part III: A diagnostic model. The Journal of Business Forecasting Spring, pp. 13-16.

Miles, M.B., and Huberman, A.M. (1994). Qualitative data analysis, Thousand Oaks, CA: Sage Publications, Inc.

Milliken, A.L. (2008). Sales \& operations planning: building the foundation. The Journal of Business Forecasting Fall, pp. 411.

Msimangira, K.A.B. and Venkatraman, S.V. (2014). Supply Chain Management Integration: Critical Problems and Solutions. Operations and Supply Chain Management 7(1), pp. 23 - 31

Neely, A. (1998). Measuring business performance: why, what and how, London, UK: The Economist Books.

Oliva, R. and Watson, N. (2011). Cross-functional alignment in supply chain planning: A case study of sales and operations planning. Journal of Operations Management 29, pp. 434448.

Thomé, A.M.T., Scavarda, L.F., Fernancez, N.S., and Scavarda, A.J. (2012b). Sales and operations planning and the firm performance. International Journal of Productivity and Performance Management 61(4), pp. 359-381.

Thomé, A.M.T., Scavarda, L.F., Fernandez, N.S., and Scavarda, A.J. (2012a). Sales and operations planning: A research synthesis. International Journal of Production Economics 138, pp. 1-13.

Tuomikangas, N., and Kaipia, R. (2014). A coordination framework for sales and operations planning (S\&OP): Syntheses from the literature. International Journal of Production Economics 154, pp. 243-262.

Van Weele, A.J. (2014). Purchasing and supply chain management. Analysis, strategy, planning and practice, London, UK: Cengage Learning

Wagner, S.M., Ullrich, K.K.R., and Transchel, S. (2014). The game plan for aligning the organization. Business Horizons 57, pp. 189-201.

Yin, R.K. (2009). Case study research: design and methods, Vol. 5, Thousand Oaks, CA: Sage Publications, Inc.

Zailani, S., Premkumar, R., and Fernando, Y. (2008). Factors influencing the effectiveness of operational information sharing within supply chain channels in Malaysia. Operations and Supply Chain Management 1(2), pp. 85-100

Hana Hulthén is a PhD Candidate at department of Industrial Management and Logistics at the Lund University, Sweden. She holds a Master degree of logistics and supply chain management from Linnaeus University, Växjö, Sweden and a Licentiate degree in Engineering from Lund University, Lund, Sweden. She has working experience in accounting and business administration. Her research related to supply chain integration and performance measures was published in journals including Benchmarking: An Int. J. and Int. J. of Physical Distribution \& Logistics Management. Hana Hulthén is the corresponding author and can be contacted at: hana.hulthen@tlog.lth.se

Dag Naslund is Professor of Process and Operations Management at the University of North Florida. Dr. Naslund also holds a position at Lund University Sweden. Areas of expertise include Process and Supply Chain Management, and Organizational Improvement Methods (Lean/Quality Management). He has taught at numerous universities throughout Europe and in 
California and Florida, and has worked with private and public organizations on organizational transformation including mapping, design and analysis of processes, design of performance measurement systems (strategic and operational), and executive training. Dr. Naslund has a significant publishing record in leading journals and his articles have received several awards. In 2013 he was the UNF Outstanding Scholar.

Andreas Norrman (Ph.D. Linköping University) is professor in Supply chain structure and organization at Lund University, Faculty of Engineering, Sweden. He has worked as a management consultant at A. T. Kearney with supply chain management and sourcing issues. His research, e.g. regarding Supply chain risk management, Incentive alignment and contracting, and the Interface between legal and logistics, has appeared in journals including Int. J. of Physical Distribution \& Logistics Management, Supply Chain Management: an Int. J., J. of Purchasing and Supply Management, Int. J. of Logistics Management, Int. J. of Production Economics, Int. J. of Procurement Management, Logistics Research, and Int. J. of Risk Assessment and Management. He has got multiple Emerald Highly Commended Awards, both as author and reviewer. 